\title{
Review of Systems Engineering (SE) Methods and Their Application to Wave Energy Technology Development
}

\author{
Pablo Ruiz-Minguela ${ }^{1,2, *(\mathbb{C})}$, Vincenzo Nava ${ }^{1,3}$, Jonathan Hodges ${ }^{4}(\mathbb{D})$ and Jesús M. Blanco ${ }^{1,2}$ \\ 1 TECNALIA, Basque Research and Technology Alliance (BRTA), Astondo Bidea, Edificio 700, \\ 48160 Derio, Spain; vnava@bcamath.org (V.N.); jesusmaria.blanco@ehu.es (J.M.B.) \\ 2 School of Engineering, University of the Basque Country, Plaza Ingeniero Torres Quevedo, 1, \\ 48013 Bilbao, Spain \\ 3 Basque Centre for Applied Mathematics (BCAM), Alameda de Mazarredo 14, 48009 Bilbao, Spain \\ 4 Wave Energy Scotland (WES), An Lòchran, 10 Inverness Campus, Inverness IV2 5NA, UK; \\ jonathan.hodges@waveenergyscotland.co.uk \\ * Correspondence: jpablo.ruiz-minguela@tecnalia.com; Tel.: +34-657-799-920
}

Received: 23 September 2020; Accepted: 17 October 2020; Published: 20 October 2020

\begin{abstract}
The design of effective and economically viable wave energy devices involves complex decision-making about the product based on conceptual design information, including stakeholder requirements, functions, components and technical parameters. The great diversity of concepts makes it extremely difficult to create fair comparisons of the relative merits of the many different designs. Conventional design approaches have proved insufficient to guarantee wave energy technologies meet their technical and economic goals. Systems engineering can provide a suitable framework to overcome the obstacles towards a successful wave energy technology. The main objective of this work is to review the well-established systems engineering approaches that have been successfully implemented in complex engineering problems and to what extent they have been applied to wave energy technology development. The paper first reviews how system information can be organised in different design domains to guide the synthesis and analysis activities and the definition of requirements and metrics, as well as the search for solutions and decision-making. Then, an exhaustive literature review on the application of systems engineering approaches to wave energy development is presented per design domain. Finally, a set of conclusions is drawn, along with some suggestions for improving the effectiveness of wave energy technology development.
\end{abstract}

Keywords: concept design; design domains; decision-making; matrix-based design methods; metrics; requirements; stakeholders; sustainable development; systems engineering; wave energy

\section{Introduction}

Humankind has always tried to make the world a better place through engineering, technology and innovation. The fundamental human needs (e.g., health, food, shelter, clean water and energy) have hardly changed over the centuries and throughout the world, but new challenges are posed as our society steadily evolves [1]. This is the case of the Covid-19 pandemic, which is confronting the world with a deep health, social and economic crisis that is upending business-as-usual. Emerging energy technologies have a broad role to play in enabling a strong forward-looking recovery and accelerating the shift to a sustainable and resilient climate-neutral economy.

Today's engineering solutions often lead to large complex products that can only be successful if they are able to meet individuals' demands, are environmentally acceptable and provide value to society. In maximising the value to stakeholders, engineers must cope with greater levels of 
complexity and interdependence of system elements. Although complexity and interdependence are characteristics that, by themselves, provide no intrinsic value, they produce vulnerabilities and risks that need adequate analysis and timely exposure to decision-makers.

The early stages of technology development are crucial in order to meet system cost and performance expectations. Actually, many authors agree that around $70-80 \%$ of the product lifetime costs are determined during the conceptual design phase [2-4]. The implication is that early design decisions are much more significant than later product development ones. Too little time spent in the conceptual design phase can lead to gaps in understanding the problem requirements, limited opportunities for novel concept generation and wasted time and money developing a concept that is unable to perform well enough to become a viable solution [5].

In order to reduce the undesirable gap between committed costs and system-specific knowledge at the early design stages, it is essential to design a process that integrates and applies the technological activities of synthesis, analysis and evaluation iteratively over the system life cycle [6]. Design traceability is also needed, as much knowledge and investment is lost at the project life cycle phase boundaries and between different projects [7]. During the design phase, the engineer is responsible for developing a comprehensive list of requirements and evaluation criteria. Thus, key metrics are established that identify the specific measures of system performance and assist in decision-making [8]. These metrics are used to scope or constrain the technical solutions. The system concept is then formalised by functional and physical architectures that meet the initial requirements. However, the process of converting stakeholder requirements into a successful design is critical. To make decisions effectively, several approaches have been developed, such as case- or knowledge-based reasoning, decision tree and matrix-based modelling methods. Amongst these approaches, the matrix-based methods are the most commonly used by engineers due to their simplicity, effectiveness and efficiency [9].

Wave energy technology is a clear example of a complex engineering product that must meet many diverse demands. Despite the increased development efforts over the last decades, harnessing wave energy continues to outfox the best engineering minds. In order to accelerate wave energy research, a systematic approach is evidently needed. Transforming wave energy into an economically viable source of energy will contribute to achieving UN Sustainable Development Goals by providing clean power (goal 7), creating jobs (goal 8), promoting energy security (goal 9), reducing $\mathrm{CO}_{2}$ (goal 13) and protecting ecosystems (goal 14).

\section{Aim and Methods}

The main objective of this work is to review the well-established systems engineering (SE) approaches that have been successfully implemented in complex engineering problems and to what extent they have been applied to wave energy technology development so far. The ultimate purpose is to share with the sector novel ideas that will help to accelerate wave energy research, support the transition to a low-carbon future and achieve the global emissions targets as established by the UN. SE methods are of great use throughout all phases of product design. However, special attention is given in this work to the early stages of technology development, since they have more impact on satisfying initial stakeholder requirements, as introduced above.

The main search terms for this critical literature review are contained in the list of keywords. References have been selected according to the quality and conformance to SE principles, including books, journal articles, conference papers, public reports and online resources. This review summarises the state-of-the-art applications of SE methods to wave energy technology development, avoiding any bias on either the SE approach used or phase covered. 


\section{Wave Energy Technology Development}

Wave energy can be considered as a derived form of solar energy. The differential solar heating of the Earth's surface creates winds, and, in turn, the action of the wind blowing across the surface of the oceans produces waves.

This largely untapped renewable energy source is attractive for several reasons: the global wave resource is abundant, predictable and widely distributed; it has a higher power density than other renewable energy sources and it can be a local resource for a large proportion of the world's population living near the coasts.

The prospect of capturing wave energy and transforming it into usable energy has long inspired the ingenuity of numerous inventors. The development of wave energy conversion can be traced back to over two centuries. The first patent to provide power from ocean waves was filed in France in 1799 by Pierre-Henri-Joseph and Philippe-Henri de Girard [10]. Since then, more than 3000 applications have been filed around the world, and this number has not yet stopped growing. The European Marine Energy Centre (EMEC) lists 243 concepts on their website [11]. The Joint Research Centre (JRC) has identified 57 companies active in developing wave energy, 40 of which are still in the early phases of development [12].

The modern history of wave energy has faced its moments of optimism and setback [13]. In the early years of wave energy development, many concepts were proposed. Progress was, however, slow and inconsistent, as inventors lacked a full understanding of the complex hydrodynamic interactions. The oil crisis of 1973 triggered a major change in the renewable energy scenario, drawing attention to wave energy. More recently, concerns about climate change and security of the energy supply, together with an increase in energy prices, renewed the interest in other renewable sources and, more precisely, in wave energy. Nonetheless, failure of the wave energy industry to deliver on the initial expectations of cost reduction has once again delayed its commercial scale development [14]. The urge to recover from the damage that the Covid-19 pandemic has caused may revamp the attention in wave energy research.

The design of effective wave energy devices is a complex endeavour that brings into play a large set of decisions. Many design parameters need to be selected at an early stage, such as the size and deployment position or the extraction principle. Even though wave-harnessing concepts are so diverse, the capture principles of most of these technologies can be grouped into a handful of main categories $[14,15]$.

- Oscillating Water Columns (OWC): Partially submerged structures open below the water surface and with air trapped above the water surface. Incoming waves make the water surface within the device oscillate, moving the air like a piston. Examples: Mutriku [16] and OceanEnergy Buoy [17].

- Hinged contour devices: Devices with two or more separate bodies that move relative to each other as a wave passes them. Energy is extracted from the reaction between the individual components. Examples: Pelamis [18] and SeaPower [19].

- Buoyant devices: Energy is extracted from the motion induced as waves pass the relatively small buoyant bodies. Examples: Wello [20] and Ceto [21].

- Oscillating wave surge converters (OWSC): Devices that extract energy from wave surges and the movement of water particles within them. Examples: WaveRoller [22] and WavePiston [23].

- Overtopping devices: Devices that are essentially reservoirs that waves fill with water. The water is then returned to the sea via a turbine. Examples: Wave Dragon [24] and Sea-wave Slot-cone Generator (SSG) [25].

- Flexible bodies: Devices incorporating flexible materials that change shape and volume due to forces imparted by a wave. Examples: Anaconda [26] and mWave [27].

The engineering challenge ahead is to develop robust machines that harness wave energy efficiently, reliably and affordably, while, at the same time, surviving the harshest seas. However, since wave 
energy technologies are so varied and their performance strongly depends on the sea state in which they are tested, it is extremely difficult to create fair comparisons of the relative merits of the many different designs. A SE approach may be of some help in this multifaceted task.

\section{Overview of Systems Engineering (SE) Methods}

SE has a relatively short history. The first documented use of this term dates to Bell Telephone Laboratories in the early 1940s [28]. Developed at Bell Labs in the following decade, SE was further refined during the successful NASA Apollo programme in the 1960s. Since then, it has evolved into a formal discipline that can be adapted to various types of product developments.

SE uses a system thinking approach to analyse engineering problems. The individual outcome of such efforts is the engineered system. A system can be defined as an interacting combination of elements to accomplish a defined objective [29].

Fundamental to SE is the notion of system life cycle [6]. The life cycle of a product begins with the identification of a need and extends through the conceptual and preliminary design, detailed design and development, manufacture and installation, operation and maintenance, decommissioning and, finally, disposal or recycling.

The need for SE arises with the increase in complexity of engineered systems. SE is a holistic, top-down approach to understanding stakeholder needs; exploring opportunities; documenting requirements and synthesising, verifying, validating and evolving solutions while considering the complete problem [29]. In fact, the ambiguity in defining the requirements and the lack of proper planning are the major factors that drive the need for a SE approach [30].

SE hinges upon several key principles. Among them, five of the most important ones are [31]:

- Abstraction. SE is based on the idea that the purpose of the design is not to produce a concrete solution but to create an abstract entity called a system. This system can then be materialised through several different solutions.

- Decomposability. A system can be broken down into separate elements (modularisation) that may cover several layers (hierarchy). These elements have an integrative architecture.

- Pluralism. The system can be addressed from complementary points of view, which must be organised in ways that permit the sharing of complex knowledge.

- Alignment. SE concerns both the product and the way the design is organised. Developing a solution requires aligning the design processes and product structure.

- Incremental improvement. Design organisation is based on "routines" that can be codified, generalised, learned and recycled from one project or team to another.

SE is about both design and decision-making [30]. The success of any complex engineering project depends upon four main activities: identifying and evaluating alternatives, managing uncertainty and risk, designing quality into a system and dealing with project management issues. The first activity is critical, as it defines the probability of success, whilst the rest of activities help the engineer to avoid any errors. A systems engineer needs to understand that decisions must be made with the best information available at the time, and therefore, they are always subject to some degree of uncertainty.

SE approaches and methods have been successfully applied in many industrial sectors (e.g., automotive, aerospace and oil and gas) to develop innovative products meeting very diverse and demanding stakeholder requirements.

Several standards have been developed for SE, such as [32-34]. Throughout the years, the initial practice-based SE has been enriched with a plethora of theoretical approaches, tools and models in different SE schools around the world [35]. Among the many methodologies used, the SE approaches can be grouped into three categories according to their primary focus:

- generic design methodologies such as systematic design [4,36] and axiomatic design [37];

- process-oriented methodologies such as concurrent engineering [38] and design structure matrix [39] and, finally, 
- design methodologies to achieve concrete goals, such as Design for X (DfX) [40], Quality Function Deployment (QFD) [41], Failure Modes and Effects Analysis (FMEA) [42] and Teoriya Resheniya Izobretatelskikh Zadatch (TRIZ) [43].

The traditional document-based SE is being replaced by abstract models as the primary means of retaining and communicating information. Model-based SE (MBSE) enhances the ability to capture, analyse, share and manage the information associated with the specification of a product [29]. MBSE helps to identify issues early in the system definition, thus improving the system quality and lowering both the risk and cost of system development.

As previously mentioned, initial ideas or expectations about the engineering system are built on a relatively insecure information basis at an early stage [44]. Frequently, neither the problem nor the solution field is particularly well-known. Therefore, a systematic and well-structured process should underpin the search for solutions and selection.

\subsection{Organising Design Information: Design Domains}

The design of a new product is an endeavour that involves a mix of creativity, technical skills and decision-making. No matter where an innovative concept may come from, its realisation should always be the outcome of a thorough design process.

Design involves an interplay between what the engineer wants to achieve and how this need is satisfied. However, there is no single commonly acknowledged sequence of steps in the design of engineering systems. The concept of design domains helps to systematise this process by creating boundary lines between different types of design activities [37].

Design domains provide engineers with an improved means of arranging design information in a way that facilitates better SE [45]. They help to organise information on requirements and to discriminate it from the information associated with design solutions. The systematic presentation of information stimulates the search for solutions and facilitates the identification and combination of essential solution characteristics [36]. Ultimately, this framework contributes to avoiding quantum leaps from the initial requirements to the physical realisations that are ad hoc, inefficient, ineffective and often lead to cost and schedule overruns [46].

Design domains structure information in particular ways to accommodate their own needs. Much attention should be paid to the consistency of information, both within and across domains. Each design domain has an associated model, which acts as a framework for capturing domain-specific information. Depending on the actual level of abstraction and degree of detail, different models can be used to represent a system in each domain [47].

Even though most SE approaches agree on the benefits of arranging design information in different domains, there is a lack of consensus on the definition of the domains that are common to all engineering projects. Table 1 presents a representative sample of design domains identified by different authors. Hyphens (-) in cells denote the authors do not cover the corresponding design domain.

Up to six different design domains are described in SE literature. However, individual frameworks normally limit their use to a maximum of three or four domains. It is worth mentioning that there is a single source [45] that considers the environmental domain in this conceptual framework. The environmental domain accounts for the exogenous components that affect or are affected by the engineering system. This domain can be characterised by system drivers and system drivers' interactions.

The stakeholder domain defines the design problem in the language of the customer, which is still general, ambiguous and highly unmeasurable. Stakeholders and their relationships represent the human components interacting with the system. Key stakeholders are those who can significantly influence the project or who are important to its success. Stakeholder needs, attributes or requirements are a set of desirable characteristics that the final solution should satisfy. Some frameworks such as [48] do not consider this domain. In that case, it is argued that the initial specifications cannot be attributed 
to one domain, as they provide an often-informal description of the required function, the technological constraints and the physical constraints.

Table 1. Design domains according to different authors. SE: systems engineering.

\begin{tabular}{lllllll}
\hline \multirow{2}{*}{ SE Approach } & \multicolumn{5}{c}{ Design Domains } \\
\cline { 2 - 6 } Suh [37] & Environment & Stakeholder & \multicolumn{1}{c}{ Functional } & Technical & Physical & Process \\
\hline Wasson [46] & Needs or attributes & $\begin{array}{l}\text { Functional } \\
\text { requirements }\end{array}$ & - & Design parameters & $\begin{array}{l}\text { Process } \\
\text { variables }\end{array}$ \\
\hline Mizuno and Akao [41] & - & $\begin{array}{l}\text { System } \\
\text { requirements }\end{array}$ & $\begin{array}{l}\text { Operations and } \\
\text { Behaviours }\end{array}$ & - & $\begin{array}{l}\text { Physical } \\
\text { implementation }\end{array}$ & - \\
\hline Pahl and Beitz [36] & - & Customer needs & $\begin{array}{l}\text { Design } \\
\text { requirements }\end{array}$ & - & Components & $\begin{array}{l}\text { Manufacturing } \\
\text { requirements }\end{array}$ \\
\hline $\begin{array}{l}\text { Hansen and } \\
\text { Andreasen [47] }\end{array}$ & - & - & $\begin{array}{l}\text { Functional } \\
\text { decomposition }\end{array}$ & $\begin{array}{l}\text { Working } \\
\text { principles }\end{array}$ & Physical design & - \\
\hline Erens [48] & - & $\begin{array}{l}\text { Transformations, } \\
\text { Functions }\end{array}$ & Organs & Parts & - \\
\hline Bartolomei [45] & $\begin{array}{l}\text { System } \\
\text { drivers }\end{array}$ & Stakeholders & $\begin{array}{l}\text { Objectives and } \\
\text { Functions }\end{array}$ & Objects & - & $\begin{array}{l}\text { (Process } \\
\text { chains) }\end{array}$ \\
\hline
\end{tabular}

The functional domain is formalised in every framework. The functional domain aims to produce a complete, unambiguous and technology-agnostic definition of the design problem space. Functions describe the purposes of the engineering system. The functional analysis in SE has the objective of defining the functional (or logical) architecture of the system and characterising its functional behaviour. It is important to note that every system operates in different phases during its life cycle (i.e., pre-mission, mission and post-mission), which need to be accounted for when identifying the appropriate functions [46].

The solution space is characterised by the technical, physical and process domains. Some authors such as $[36,47,48]$ distinguish the technological realisation of the design problem consisting of a set of modules, organs or solution principles from the physical implementation of the technologies that are allocated or distributed into components and parts. Together, the technical and physical domains describe the physical embodiment to achieve the system functions.

Finally, the process domain determines the process variables, manufacturing requirements and activities that enable the production of specific components and assemblies to achieve the final system. Some authors exclude this domain from their frameworks, as they mainly focus on conceptual and embodiment design.

\subsection{Propagating Design Information: Matrix-Based Modelling Methods}

System design requires integration and iteration activities, invoking a process that coordinates synthesis, analysis and evaluation over the system life cycle. Design is the result of a series of mappings across design domains, as shown in Figure 1. The design of an engineering system is hindered if these domains are not linked in a consistent way.

Design takes place both within and between domains. The successful transition from different domains requires effective design synthesis and analysis processes. Moving from left to right illustrates the engineer's synthesis activity from what is required to how to achieve the design that satisfies the requirements. Conversely, moving from right to left shows the engineer's analysis activity, which supports validation and verification. Synthesis is to be understood as a creative step, whereas analysis represents a critical step. The analysis drives the evaluation process and, therefore, the design decisions. 


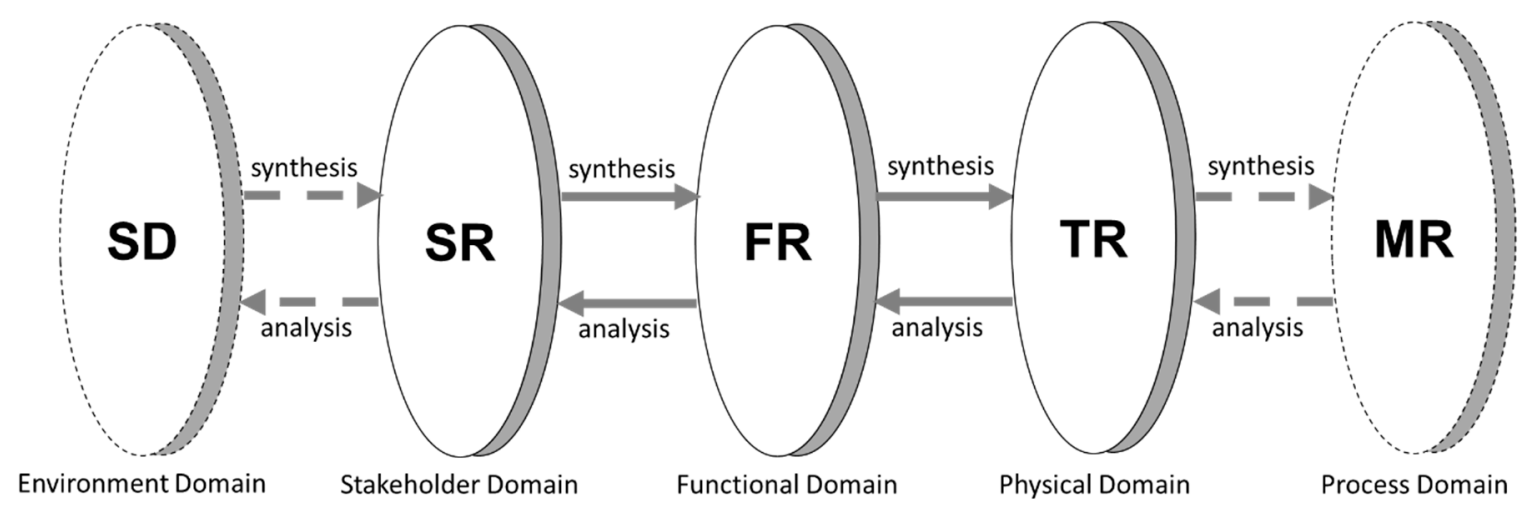

Figure 1. Domains of the design world (adapted from [49]). System Drivers (SD), stakeholder requirements (SR), functional requirements (FR), technical requirements (TR) and manufacturing requirements $(\mathrm{MR})$.

It is worth noting that the three central domains are also consistent with the design processes of the V-model [50], a popular SE approach. The V-model establishes a relationship between the phases of system design definition and its associated phases of system integration and evaluation.

Matrix-based design methods enable designers to arrange information, understand complex interactions, quantify interrelationships and propagate information across design domains. These methods sequentially transform design information across domains, starting from system drivers (SD) to stakeholder requirements (SR), functional requirements (FR), technical requirements (TR) and manufacturing requirements (MR). The translation of design information across domains should be performed to ensure full traceability of the design. The purpose of traceability is threefold [51]:

- manage engineering changes across the system development,

- understand the decomposition of the system at each hierarchical level and

- manage the overall quality of the developed system.

There are several well-established matrix-based modelling frameworks [52]. These include intra-domain models such as the design structure matrix introduced by [53] and extended by [39]; inter-domain models such as the cause and effect matrix [54], the interface structure matrix [55] and the domain mapping matrix [56] and multiple-domain models such as the unified program planning [57], QFD [41], axiomatic design [37], the function transformation matrix [58] and the engineering systems multiple-domain matrix [45].

Figure 2 presents a conceptual representation of intra-domain dependencies (i.e., diagonal matrices A-B-C, 1-2-3-4 and $\alpha-\beta-\gamma-\delta$ ); inter-domain dependencies (e.g., A-B-C $<->1-2-3-4$ matrices) and multiple-domain dependencies (i.e., full matrix). 

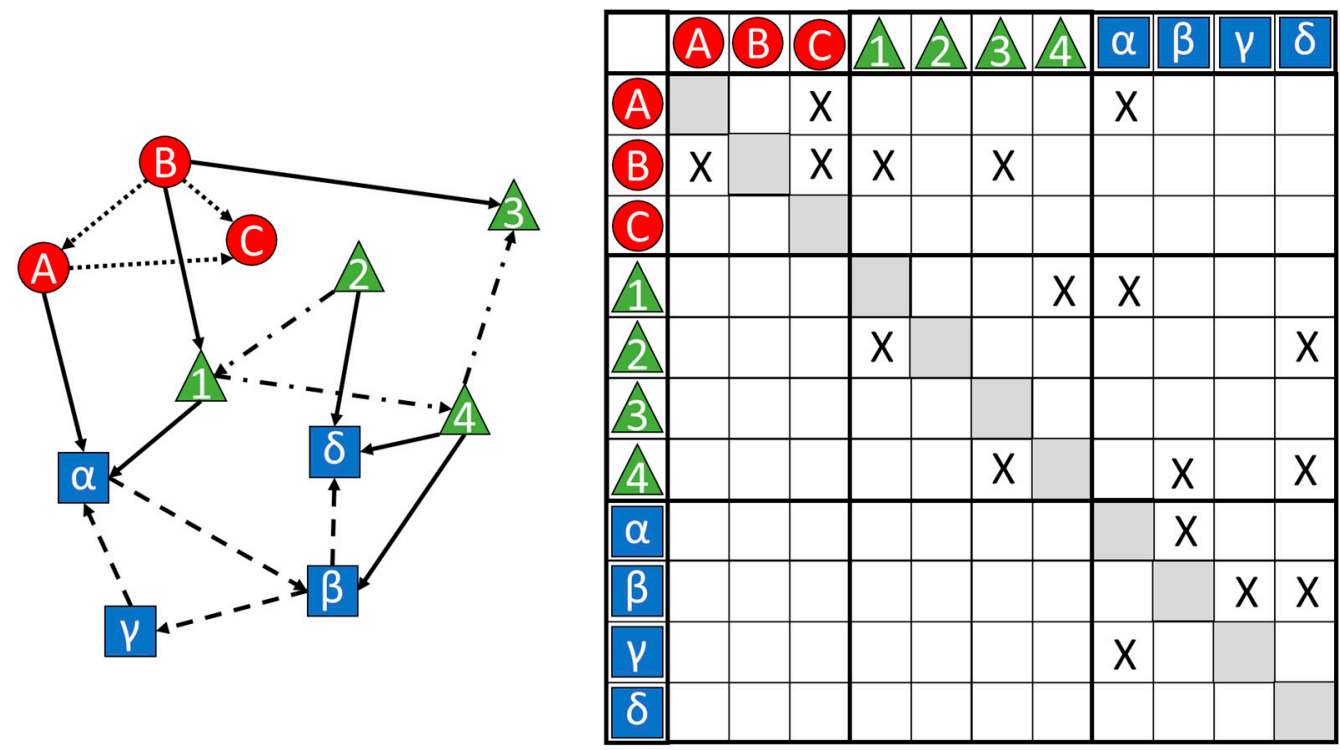

Figure 2. Representation of dependencies in a multiple-domain model (adapted from [52]).

\subsection{Defining the Problem Space: Requirements and Metrics}

The aim of the formulation of requirements is to build a systematic summary of the purposes that should underlie the search for solutions. A specification of requirements establishes the agreement of the technical capabilities and levels of performance required for an engineering system to achieve its mission and objectives within a prescribed solution space [46].

Requirements that bind a solution space are hierarchical and interrelated. They can be broken down at different levels of detail and should be fully traceable within and through the various design domains. At the high level, requirements focus on what should be achieved and not on how to achieve it. According to [59], a specification of requirements should be complete, whereas individual requirements should be characterised by the following set of features: necessary, concise, achievable, complete, consistent, unambiguous and verifiable.

The satisfaction of requirements is the driving force behind SE. Therefore, the verification and validation of those requirements is equally important to successful SE. Decision-making is supported when the requirements at all levels can be balanced and evaluated against each other [60]. Verification and validation are evidence-based processes that rely on metrics and data to assess whether a system meets the specifications of the requirements. The metrics must be well-defined and articulated for an effective verification and validation.

Using the classical SE V-model, Figure 3 visualises the various levels of hierarchy, showing the interrelations of requirements-based system definition processes with the corresponding metrics-based verification and validation processes.

At the top level, the specification captures all essential and prioritised stakeholder requirements that fit within the technical, financial and risk constraints. SR comprise operational requirements, which define the major purpose of a system, together with the key system constraints, such as physical attributes, overall performance and quality features [61]. Stakeholders may well begin with desires and expectations that contain vague, ambiguous statements that are difficult to use for SE activities. Care must be taken to ensure that those desires and expectations are transformed into a set of clear and concise requirement statements that are useful as a starting point for system definition [29].

The SR identify specific properties of the system that are needed to satisfy the end-user or stakeholder. Once the critical system properties are established, metrics must be assigned to offer the system engineer a means by which to assess various solutions. Metrics that are linked to the system operational objective, performance, suitability and affordability are usually referred to as Measures of 
Effectiveness (MOEs). MOEs are quantified outside the system [62]. MOEs should not be strongly correlated to each other, in order to provide insight into different operational aspects of the technical solution or solution alternatives. Since the other two evaluation metrics are successively derived from MOEs, their number should be reduced, often one for each major output from the system. Results from a questionnaire in [63] showed a range of two to 12 MOEs, with an average of six.

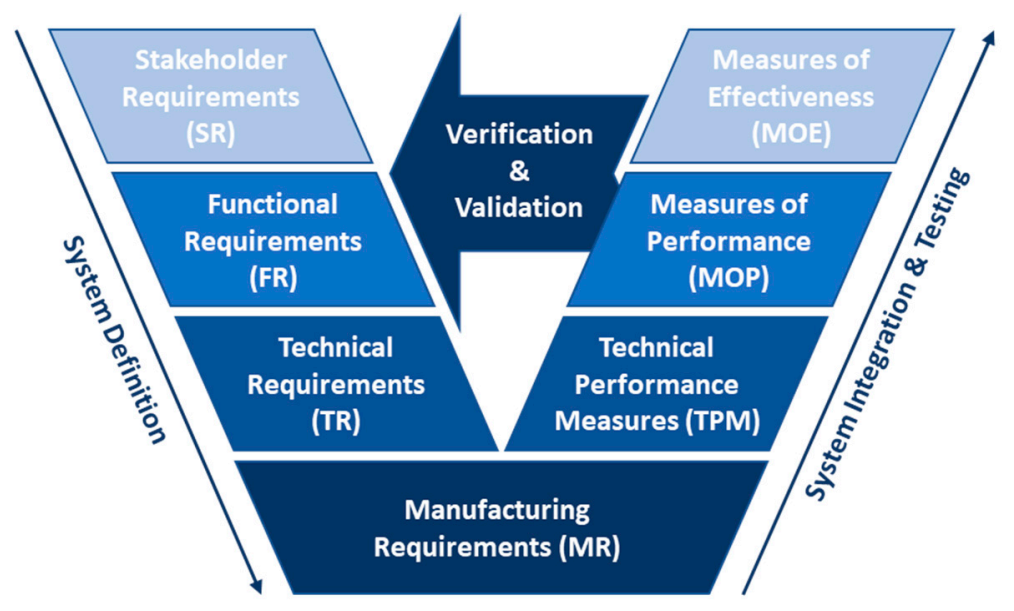

Figure 3. Requirements and metrics in the systems engineering V-model.

At the next level, the specification moves onto the functional requirements. FR specify what the system must do in order to achieve the SR, but they do not address how the system should accomplish it. In other words, a FR should not go into the details of how to implement the function. FR establish the intended purpose of a product, its associated constraints and environment, the operational and performances features for each relevant situation of the life cycle and the permissible flexibility [64]. They produce a complete, unambiguous, technology-agnostic definition of the design problem space and are the baseline for investigating and comparing candidate concepts. FR are the bridge between the stakeholders and technical teams.

A system's capability is characterised by a function and a its level of performance [46]. Measures of Performance (MOPs) are used to specifically gauge the capabilities of a design solution. Hence, establishing the MOPs will involve the tracing of FR through the functional breakdown of the system in order to specify a measure. Traceability should be maintained both throughout the decomposition process and with regard to the higher-level MOEs. MOPs are measured from within the system [62]. There are generally several MOPs (range of one to 10) for each MOE, with a recommended average of five [63].

Technical requirements define the issues related to the technology that must be considered to successfully implement the system in physical parts and assemblies. TR are dependent on the design solution and, therefore, are sometimes called design requirements. Design variables characterise the actual free space for creating solutions [44]. Whilst FR describe what the system must do, TR focus on how the system does it. TR need to be compatible with the intended purpose of the system and its associated constraints and environment, as well as the operational and performance features for each relevant situation of its life cycle [64]. They are, thus, the practical baseline of the agreement for the technical team to design and develop the selected solution.

The key indicators used to demonstrate a compliant and successful delivery of the specific and detailed technical requirements are called technical performance measures (TPM). Selection should be limited to critical technical thresholds and goals that, if not met, put the project at risk in terms of cost, schedule or performance. They are usually derived from MOPs. Generally, there is at least one TPM per MOP, but often, there are several TPMs (range of one to seven) per MOP, with a suggested average of four [63]. 
Last, but not least, manufacturing requirements are used to ensure producibility in early development phases and as a source for continuous improvement of the manufacturing system [60]. MR are normally considered as constraints, since they limit the engineering system design. MR are derived both from the TR product (i.e., product) and the manufacturing system (i.e., manufacturing resources and processes being used). They comprise the materials, equipment and process parameters needed to produce the engineering system. As with any other system, MOEs can be used to measure the manufacturing system operational objective, performance, suitability and affordability.

\subsection{Search for Solutions, Evaluation and Selection}

The search for solutions is a constructive and creative step in SE. Its purpose is to develop solution variants appropriate to the level of detail in each design phase from the results obtained during the problem definition [44]. The level of detail of the variants should be suitable to allow comparison and selection of the most appropriate one.

Several systematic search strategies can be used depending on whether the solution space is navigated in a linear or a cyclical fashion. In some cases, mathematical algorithms can be used to find the optimal solution. However, to apply these techniques, it is necessary to develop quantitative models, and this renders their implementation difficult in complex engineering systems, or, at least, they are only applicable to partial design areas. Search processes can be improved and supported by intuitive work that uses heuristics [65], based on a deliberate transfer of analogies, similarities or even oppositions as the TRIZ algorithm [43].

Solution alternatives are examined following a critical analysis process regarding their adherence to the initial requirements. Only suitable alternatives are evaluated. Evaluation criteria are required for signifying which qualities or effects are considered essential. The various categories of metrics defined in Section 4.3 serve both for solution validation and a comparison of alternative solutions.

Multi-criteria analysis methods are used to inform the decision-making process for the selection of solutions in complex engineering problems, particularly when alternative solutions can be heterogeneous. Many methods have been developed to solve different types of decision problems. However, the decision-maker is faced with the arduous task of selecting an appropriate decision support tool [66]. One way to address this task is to look at the modelling effort (i.e., required input data) and the granularity of outcomes (i.e., feasible solution and partial or complete ranking). At the highest modelling effort, the MAUT (multi-attribute utility theory) [67] is used when a representation of the perceived utility for every selection criterion can be built. At a medium scale of modelling effort, AHP (analytical hierarchy process) methods [68] use pairwise comparisons between the criteria and options. Finally, at the lowest end of the modelling effort, a DEA (data envelopment analysis) [69] is mostly used for performance evaluation or benchmarking, where no subjective inputs are required.

The aggregation concept is a common feature of all the multi-criteria analysis methods. However, all evaluation criteria are not equally important; some are so important that their satisfaction, above a threshold, is mandatory, but others can be optional. The most used aggregation method is the well-known arithmetic mean. It allows full compensation and can be used when combining scores that measure similar attributes. Conversely, the geometric mean and harmonic mean do not allow any compensation and should be used when combining disparate attributes. The LSP (Logical Scoring of Preference) method proposed by [70] adds more granularity to the aggregation step by allowing definition of the degree of simultaneity of the attributes being combined from total disjunction to full conjunction.

Any decision has several favourable and unfavourable concerns to consider. The favourable, certain concerns are called benefits (B), while the unfavourable ones are called costs (C). The uncertain concerns of a decision are the opportunities $(\mathrm{O})$ that the decision might create and the risks $(\mathrm{R})$ that it can entail. The analysis of BOCR offers a structural framework to get all the necessary information for effective decision-making [71]. The system merits in BOCR generalise the traditional cost-benefit 
analysis and the concept of cost, benefit and harms in TRIZ. Figure 4 presents the aggregation hierarchy for the four types of concerns, namely benefits, opportunities, costs and risks.

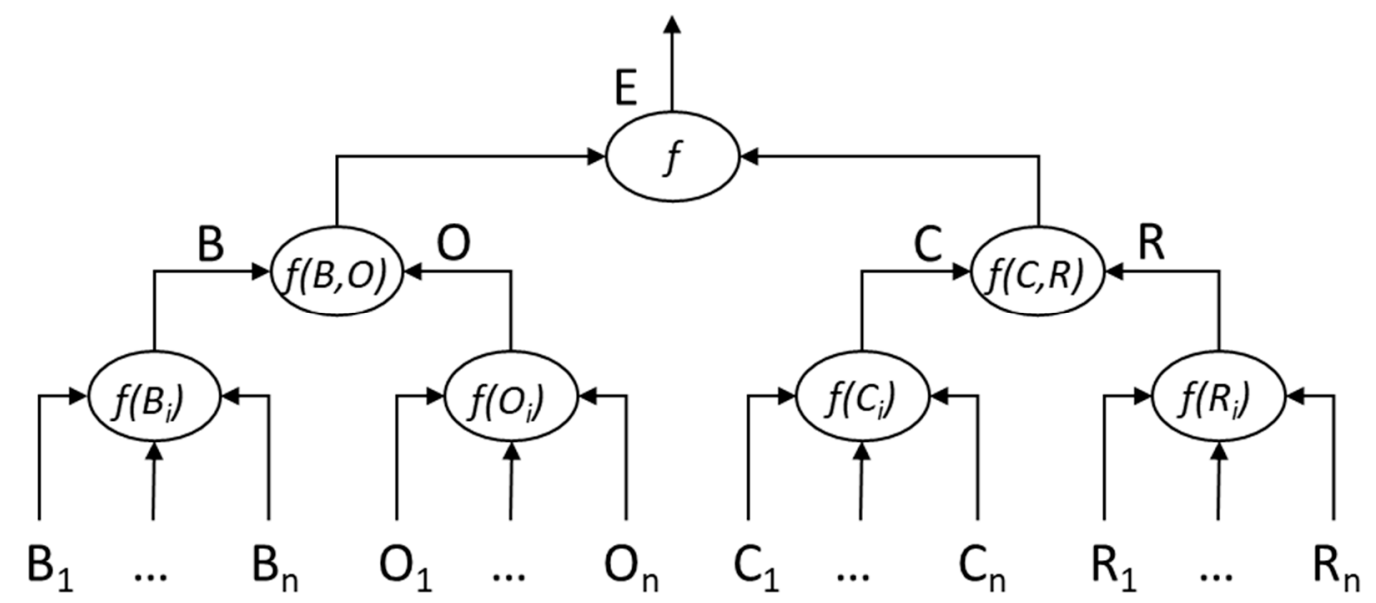

Figure 4. Aggregation hierarchy of the evaluation criteria. BOCR, benefits, opportunities, costs and risks.

Solving a real problem in a linear fashion is seldom achievable. The SE approach can be applied in an iterative way to move towards an acceptable solution to a problem situation within a larger cycle of stakeholder value [29]. The evaluation is repeated at increasing levels of technological maturity as the concept progresses from an initial idea to a fully tested and proven system. This iterative risk-based analysis method to product development is formalised in SE through the spiral model [50] and the stage-gate model [72]. Over the years, SE has developed many tools and techniques for risk management, such as FMEA [42], fault tree analysis (FTA) [73], fuzzy logic [74], Bayesian analysis [75] and Monte Carlo simulation [76]. Established early in the project, the system metrics achieved at any stage are compared to the design goals and improvements implemented if necessary to achieve these goals.

\section{Application of SE Methods to Wave Energy}

Wave energy converters (WECs) are complex engineering systems, and product development is inevitably multidisciplinary. So far, wave energy development experience shows that excellence in each discipline is a necessary but not sufficient condition to achieve a viable product. SE provides a suitable framework for a holistic approach that might allow progress towards a successful wave energy technology [77].

The need for a more comprehensive systems perspective to the development of wave energy technologies was also highlighted in a recent workshop on the identification of future emerging technologies in the ocean energy sector [78]. The report points out that some practical aspects neglected at an early stage can become a problem if taken up at a later stage, and therefore, technology developers should move from a sequential to a system design process. In order to overcome failures previously experienced in the sector, an integrated systems approach is required to develop wave energy systems; subsystems cannot be developed in isolation.

Similarly, the application of SE principles has been recognised by sector experts as a way to accelerate marine energy research [79]. Survey results of this research recommended focusing on common components to enable affordable ways to harvest marine energy and not on specific technologies. Experts also suggested proving that a system works reliably, checking its functionality in the early project stages and, consequently, focusing on end-user requirements.

As presented in Section 3, WEC concepts span a wide design space [14]. The great variety of concepts makes it extremely difficult to identify common design approaches. Moreover, there is little 
published work on the specific design methods used in developing these devices, since most of the technology developers are private companies.

Nevertheless, a small fraction of technology developers does claim to have used a SE approach in their development process. The authors have identified the following five practical examples in the literature review:

- Wavebob [80] described the concept of SE in its application to WEC design. The method ensures the essential identification of technological barriers at an early stage of the system development, alleviating unnecessary technology cost and reducing development, operational and corporate risk, while shortening the development time.

- Martifer [81] implemented SE for the systematic selection of candidate architectures and the definition of functional requirements for system design and development.

- The utility company PG\&E [82] used a formal SE approach in the development of WaveConnect, a wave energy pilot project, to demonstrate the long-term viability of harnessing ocean wave energy for electricity generation on a commercial scale.

- Waves4Power has used SE to propose new mooring solutions for the WaveEL device and array systems regarding their survivability, serviceability and profitability [83].

- AWS has applied a SE approach to the front-end engineering design activities of the AWS-III WEC [84].

Even though some companies seem to be aware of existing SE methods, it is a strikingly recent phenomenon (only documented in the last 10-year timeframe). Additionally, the application of SE might have been limited and fragmented, since these technology developers have not been free from suffering expensive, high-risk, slow, rigid and discontinued technology developments.

The application of SE to wave energy technology development is reviewed in more detail in the following subsections.

\subsection{Environmental Analysis}

The environmental domain recognises that the wave energy system exists within a context in which multiple SD are influencing its conception, planning, and operation. The SD include the political, economic, social, technical and environmental factors that constrain, enable or alter the design solution.

The authors of [85] presented the context diagram used to define the external systems that can directly influence the success of a grid-connected wave energy farm. This list identifies the factors that are out of the control of the external systems and the farm (i.e., political, social and economic climates). It is pointed out that the overarching context can influence the external systems and the success of the farm. However, the SD are not specifically analysed.

The authors of [86] analysed the critical factors to the commercial viability of WECs in off-grid luxury resorts and small utilities using political, economic, social, technological, legal and environmental (PESTLE) tools and Porter's five competitive forces. Factors like the available wave resource, distance from shore, existing infrastructure, power demand, supply chain logistics, alternative energy sources and current cost of energy were found to have large impacts. The authors acknowledged that the factors discussed may not affect the viability of off-grid systems in the same way as in grid-connected systems.

The authors of [87] carried out a similar analysis to reveal the risks and uncertainties that face large-scale grid-connected wave and tidal energy projects. This work showed that, although the political, economic and social aspects have great importance, the technological barriers are key in order to attract investors.

The Pacific Northwest National Laboratory (PNNL) and National Renewable Energy Laboratory (NREL) are conducting a three-year project to review the grid value for marine energy development at scale on an intermediate-to-long-term horizon. Grid values are arranged into three categories: the spatial or locational aspects of marine energy, the temporal or timing aspects and special applications to ensure most situational benefits are captured [88]. 
Finally, the H2020 DTOceanPlus project presented a summary of nontechnical barriers and enablers to wave and tidal stream commercialisation in its public deliverable D8.1 [89]. The factors listed from literature sources comprise private and public financing, insurance, continued cost reduction, supportive consenting and regulation, infrastructure, standards and certification, innovation and cross-sectoral interlinkages, together with ethical and environmental concerns.

Attributes that characterise the SD are fairly covered for wave energy, but there is no reference to how these SD interact among each other and are prioritised.

\subsection{Stakeholder Analysis}

The stakeholder domain aims to define the design problem in the language of the customer and other related actors. Wave energy stakeholders can be defined as individuals, collectives and organisations who have an interest in wave energy technologies, who can influence project development or be affected by the project, as well as those who can directly or indirectly impact the decision-making processes [90]. Key stakeholders will be those who can significantly influence the technology and project development or are central to its final success.

The stakeholder analysis involves the identification and prioritisation of stakeholder groups, eliciting and ranking SR, as well as defining system merits or MOEs.

The review of the literature reveals very diverse classifications of stakeholders for marine energy projects. For instance, in [91], the following six main stakeholder groups are identified:

- project designers and developers;

- national, regional and local governments and public authorities;

- potential member companies and partners;

- financial institutions;

- knowledge institutes and

- environmental organisations.

However, the FP7 EQUIMAR project [92] considers stakeholders during the entire project life cycle. At the initial stages of project development, owners, developers, suppliers, employees, the government, unions and individuals or whole communities located near or at the vicinity have a key influence. When operational, creditors and end energy users can be included as well, stakeholders are then grouped into four categories:

- Statutory consultees: authorities, agencies, groups or bodies defined in local, national or international legislation, which the developers are obliged to consult.

- Strategic stakeholders (nonstatutory consultees): local, regional, national or international organisations (and their representatives) who have important information, experience and expertise.

- Community stakeholders: any individual, groups of individuals or organisations whose lives, interests and welfare can be affected by the development.

- Symbiotic stakeholders: owners or organisations who may have an interest on or may have mutual benefits from a co-development.

More recently, in [93], twenty-six wave energy stakeholders are identified who are grouped into four categories:

- Highest-level stakeholders. Customers of the wave energy project (e.g., utility companies but, also, investors and financiers) or stakeholders that do not have direct economic interest in it.

- Core stakeholders. Project developer, owner, construction company and farm operator.

- First-tier suppliers. These stakeholders have direct interaction with the WEC farm core stakeholders by providing major services or subsystems required to build the wave energy project (e.g., WEC units or marine operations). 
- Low-tier suppliers. They do not interact directly with the core stakeholders. They are suppliers to the first-tier suppliers.

Although the above shows some underpinning research to assist in the identification of wave energy stakeholders, to the best of our knowledge, there is no public reference on stakeholder prioritisation in this sector. Stakeholder mapping techniques, usually based on two or three dimensions (e.g., power, interest and urgency), have been used in other sectors to determine the priority of identified stakeholders [94,95].

The elicitation of SR largely depends on the type of market being addressed. As explained in the Section 5.1, the environmental domain accounts for the factors linked to the added value to the intended market.

Both Wavebob [80] and utility company PG\&E [82] mention the use of SE to reflect end-user needs and to develop the top-level requirements.

To date, the Wave-SPARC project [96] has produced the most comprehensive analysis of the wave energy stakeholder domain. Wave-SPARC has delivered a complete and agnostic formulation of a utility-scale wave energy project through the application of SE and a stakeholder analysis. The analysis of stakeholders' needs in [93] led to seven high-level SR and a total of 33 low-level SR. Costs and risks are clearly identified as two of the high-level requirements. The other five categories contain a mixture of benefits (reliable for grid operations), opportunities (benefit society and deployable globally) and risks (acceptability and safety).

SR are not ranked/weighted according to their relative importance. However, the concept of requirement flexibility is introduced to carry out their aggregation into higher-level requirements [93]. A technical solution may not fully satisfy one low-level requirement, but a trade-off with another requirement may make the higher-level requirement still viable. Four degrees of flexibility are identified, ranging from high flexibility to none.

SR identify specific properties of the system that are needed to satisfy the end-user or stakeholder. Once the critical system properties are established, metrics must be assigned to offer the system engineer a means by which to assess various solutions. The list of requirements that have been developed in Wave-SPARC serve as the components of the technology performance level (TPL) metric [97]. The seven capabilities groups meet the seven high-level SR and constitute the ultimate metrics a utility-scale wave energy project must satisfy:

- $\quad$ C1: Have market-competitive cost of energy.

- C2: Provide a secure investment opportunity.

- C3: Be reliable for grid operations.

- C4: Benefit society.

- C5: Be acceptable to permitting and certification.

- C6: Be safe.

- C7: Be globally deployable.

In order to rank SR, Jahanshahi et al. [98] took a different approach. They applied the Delphi method to assess the economic requirements and their relative importance for the development of the wave and tidal energy technologies based on the experts' judgment. Operational costs and revenue were ranked as the most important criteria from the experts' points of view. Preoperation costs and investment, incentives, profitability and externalities were ordered in the next priorities, respectively. It is worthwhile noting that both the incentives and externalities are SD and, thus, should belong to the environmental domain.

\subsection{Functional Analysis}

The functional analysis in SE has the objective of defining the functional architecture of the system and characterising its functional behaviour. FR are the bridge between the stakeholders and technical 
teams, and they shall be specified at each stage of the system life cycle. Thus, a necessary step is to identify all these stages.

Wavebob [80] defined operational scenarios right through from transportation, assembly, installation and commissioning to operation, maintenance, support and decommissioning. More recently, Babarit et al. [93] identified six life cycle stages for a wave energy farm: engineering, procurement, construction, installation, operations and disposal.

The authors of [99] proposed a systematic approach for the design of WECs, identifying the functions, selecting those having an important bearing on cost and trying to find ways of performing those functions economically. This systematic approach for the early or conceptual stages of design is described in [100]. The design of WECs is exemplified through the analysis possible combinations of three main functions: provide a working surface, provide a reaction force and extract power. Providing the reaction force is the dominant function in designing affordable devices. It results, apparently, in this approach focusing on the specification of FR during the operational phase of the technology.

The University of Uppsala has applied a systems approach to develop ways to harness wave energy, which considers manufacturing, maintenance and compatibility with the natural environment early in the design process [101]. These criteria are not normally used for down-selecting a concept from a set of solutions that achieve a desired functionality.

Technology developer Martifer [81] implemented a SE approach for the systematic selection of candidate architectures and a definition of FR for system design and development. Similarly, the utility company PG\&E [82] developed a set of functional block diagrams to identify functional relationships between system infrastructure segments and to external systems in the WaveConnect project. The authors of [102] described the functions performed by the OWC power plant to convert wave power into electricity.

Partial coverage of FR can be found in [103], where FR are formulated in the context of wave energy conversion but only for the mooring system, and [104], who has produced a comprehensive landscaping report for wave energy Scotland (WES) on FR for WEC controls. The authors of [105] presented a functional analysis of the submergence system for a Spar OWC in the form of an octopus diagram, exposing the elements interacting with the system and the main functions (service and constraint). The functional analysis resulted in a set of functional specifications showing the expected system functions, the judgement criteria, the levels of these criteria and the flexibility.

The authors of [97] presented a full taxonomy of FR for a wave energy farm. The five top-level functions identified what the wave energy farm must do to meet its mission. The subfunctions below the top levels further decomposed the top-level functions (e.g., WEC or electrical substation). These subfunctions identified the unique aspects that must be achievable to satisfy the higher-level function. A further breakdown was given to subfunctions in the form of sub-subfunctions, further focusing in on the details that were needed (e.g., power take-off (PTO) within a WEC). At each level, the functions were mapped to capabilities through MOPs.

In 2009, EMEC introduced some guidelines for functional performance measures of marine energy conversion systems, such as reliability, maintainability and survivability [106]. At a high level, performance metrics require design and systems engineering, and, at a lower level, components are able to fulfil these requirements. This is not necessarily captured by the contemporary TRL (technology readiness level) assessment. This is the reason why [107] examines the key performance metrics that underpin Levelised Cost of Energy (LCOE) (i.e., Capital Expenditure (CAPEX), Operational Expenditure (OPEX), yield, reliability, cost of finance, survivability, durability and project size).

Since 2014, Wave-SPARC [96] has been developing and applying holistic and quantitative technoeconomic assessment metric systems to identify technology weaknesses and strengths to, ultimately, advance technology towards their markets applications. This de-risking approach is applicable to all WEC systems that are currently under development and to the novel systems invented in the project. The system performance is measured through the TPL metric. The development of 
TPL assessment criteria, methods and tools was first introduced in [108], further developed in [109], and practically applied and enhanced in the Wave-SPARC project.

Similarly, since 2016, WES has been promoting the development of performance metrics and tools for ocean energy technologies via workshops with a wide international cross-sector input [110]. This work is being further developed within the EU H2020 funded project DTOceanPlus [111] and International Energy Agency Collaboration Programme for Ocean Energy Systems (IEA-OES) Task 12 on an International Technology Evaluation Framework for Ocean Energy [112]. The authors of [113] contributed to gaining an international consensus by compiling a list of existing ocean energy performance metrics for the farm level; the wave energy device and its main subsystems (e.g., structure, PTO, control and mooring).

The analysis of FR for wave energy systems is reasonably well-covered in the literature. There is also a growing awareness on the need to define functional performance measures to judge the success of wave energy technologies beyond the TRL assessment [114]. Based on US and EU progress, there is ongoing work to gain an international consensus on the development of performance metrics. Although this is very positive, there is still the need for methods that establish the relative importance of FR and their interactions.

\subsection{Technical/Physical Analysis}

The technical and physical domains describe the physical embodiment required to achieve the system functions. Functional architectures contain logical decompositions of high-level functions into lower-level functions. High-level functions occur in the operational environment, which dictates how the system must work at the level of operators. Lower-level functions are allocated to the physical architecture of the system [30]. Therefore, TR are dependent on the design solution.

An overview of the key subsystems that require consideration for wave energy systems is provided in [115-117]. According to these sources, the WEC can be characterised in five main subsystems, namely the reaction system, power take-off, hydrodynamic system, power transmission and control. Due to the large number of existing WEC devices, it is impossible to analyse all potential decompositions. Alternatively, a high-level system breakdown in [115] identified eight different categories of combinations between the diverse hydrodynamic and reaction systems relevant to the WEC industry.

The authors of [118] presented a comprehensive functional analysis, technical breakdown and mapping of the system requirements to the main cost centres of a WEC, i.e., the rotor, PTO, substructure, installation and maintenance operations. However, all technology developers are required to develop a system decomposition and functional allocation, either implicitly or as a result of a more systematic process.

Wavebob [80] and Waves4Power [83] are two examples of technology developers where system decomposition and functional allocation has been documented. In the case of Wavebob, this process was mainly driven by reliability concerns. The analysis of the failure mode effects provided the quantitative information on system availability to inform on the need for increased system redundancy or modularity, in turn providing invaluable information on the appropriateness of system designs at an early stage of the development. As regards Waves4Power, this process was used to propose new mooring solutions for the WaveEL device and array systems in terms of their survivability, serviceability and profitability. Evaluation matrices were used to compare alternative mooring concepts.

There are several standards and guidelines that have been produced to assist in the development of the TR and assessment of technical performance:

- EMEC has issued some guidelines for the grid connection of marine energy conversion systems [119].

- International Electrotechnical Commission (IEC) TS 62600-2:2019 provides design requirements to ensure the engineering integrity of wave, ocean, tidal and river current energy converters, collectively referred to as marine energy converters [120]. 
- IEC TS 62600-100:2012 provides a systematic method for assessing the electrical power production performance of a WEC [121].

- IEC TS 62600-30:2018 specifies the electrical power quality requirements of a marine energy (wave, tidal and other water currents) converter unit [122].

As TR are quite specific to the design solution, there is little information on the TPMs used to make decisions on the design options explored and sizing of the components.

\subsection{Process Analysis}

The process domain determines the process variables, manufacturing requirements and activities that enable the production of specific components and assemblies to achieve the final system. Manufacturing readiness levels (MRL) are commonly used to measure progress on the effectiveness of producing specific components and assemblies [114]. The identification of manufacturing risks must begin at the earliest stages of technology development and continue vigorously throughout each stage of the system design.

There are no references in the literature to the development of MR specific for WEC devices. The EMEC has produced some guidelines for manufacturing, assembly and testing of marine energy conversion systems [123]. This document does not contain a list of MR, but it could be used to inspire the development of MR.

\subsection{Evaluation and Selection}

Evaluation throughout the wave energy technology development path has usually been based on the TRL assessment, as presented before. Several TRL definitions specific to wave energy have been proposed $[124,125]$. However, readiness levels assess the maturity and risks within the wave energy development process rather than its quality, technical or economic performances.

Evaluation methodologies based on the LCOE have been at the very centre of wave energy technology development. LCOE combines in a single metric two important stakeholder requirements, namely lifetime costs and energy production. This method is akin to well-known cost-benefit analyses [36].

Reversed LCOE engineering [126] is a methodology to explore the limits for the technical parameters of a WEC. In this approach, an LCOE target is set, and the upper cost limits for the main subsystems of the WEC are obtained. Learning rates due to factors such as the production volume and automation can also be considered in order to assess whether the cost limits for a subsystem can be reached from the current costs. This methodology relies on prior knowledge of the allocation of cost centres to the physical realisation. It provides guidance for existing prototypes on how to improve their commercial attractiveness but does not guarantee the stakeholder value is maximised.

The authors of [127] proposed a new methodology that can be used to account for both risk and the LCOE to give a clearer picture of the feasibility of a WEC development.

Beyond costs and risks, Bull et al. [97] proposed an integrated TPL metric. The lowest level system capabilities are scored and progressively aggregated following a mathematical calculation. There are three different ways of combining the lowest level scores: arithmetic mean, geometric mean and multiplication with normalisation. The overall score is calculated from scores for the seven high-level capabilities arranged into three categories (weighted average of individual geometric means). However, due to the scoring complexity, this approach requires expert assistance to perform the assessment. In the public version of the tool, the weighting of the different criteria is fixed. The TPL assessment cannot be adapted to changing market conditions or stakeholders' expectations, which will incidentally hinder the traceability of system requirements across domains.

Inherent to the performance assessment, there is the concept of staged development. Stages are loosely related to the TRL scale. At each stage-gate, an evaluation of the relevant metrics is done. Different stage frameworks have been proposed. The most common one consists of five stages. 
This systematic development plan was initially proposed for WECs of a buoyant type to mitigate the financial and technical risks during development at the Hydraulics \& Maritime Research Centre of the University College Cork (HMRC) [128]. Later, it was adopted as the best practice by IEA-OES [129] and FP7 EQUIMAR [130] and, finally, recommended by the IEC [131]. A WEC or subsystem must fulfil the stage-gate criteria at the end of each stage before passing to the next development stage. A simplified approach consists of three stages. The project and/or the technology deployment are split into early, mid and late stages [112,132].

The authors of [133] presented a series of considerations to specify the requirements of relevant, realistic and effective assessment criteria, methodologies and tools for wave energy technologies. Among them are the measurability, level of accuracy, granularity, validation, reference values and thresholds for the assessment criteria.

The authors of [5] proposed a set-based design (SBD) approach for concept selection. Designers can avoid choosing a concept based on imprecise data by developing many concepts and eliminating the inferior ones instead of selecting one concept for further development and iteration. Trade-offs and preferences can be included when evaluating concepts by combining the utility analysis with SBD methods. When applying utility-based decisions in SBD, designers create a utility function that weighs each attribute of the concept. Within each attribute, the concept is given an interval score. The interval score allows the designers to account for the span of possible values given the imprecision of the conceptual design.

The project SEAWEED is also developing a structured approach to concept creation and selection [134] focused on the direction of early stage concept creation activity towards promising areas of investigation rather than the definition and evaluation of detailed technical solutions.

Finally, DTOceanPlus is developing design tools for the assessment of ocean energy arrays, devices and subsystems at different development stages [111]. Assessments are grouped into four main categories, namely SPEY (System Performance and Energy Yield); RAMS (reliability, availability, maintainability and survivability); SLC (system lifetime costs) and ESA (Environmental and Social Acceptance). These assessments will feed into a stage-gate metric tool for the overall assessment of ocean energy technologies.

Wave energy system development, evaluation and selection is moving progressively from simplified approaches such as assessing the technology maturity and cost to more holistic performance measures. Selection at intermediate stages of the system design contributes to reducing the risks. Iterations at low TRLs until the desired performance is achieved will contribute to the analysis of the solution space and production of more cost-effective designs.

\section{Conclusions}

This paper reviewed the main SE methods applicable to early design stages, where most of the final costs and performance characteristics are determined, as well as their utilisation in wave energy development. Transforming wave energy into an economically viable source of energy and jobs will be key to a strong forward-looking "green recovery" from the Covid-19 pandemic and achieving UN Sustainable Development Goals.

The development of wave energy systems involves complex decision-making about the product based on conceptual design information, including the stakeholder requirements, functions, components and technical parameters. Stakeholders play an important role in the development of system innovations, as their expectations greatly influence the future of such innovations, until the potential benefits are realised through practical application. Therefore, it is paramount that SR are fully traceable throughout the design process. An SE approach may help in this multifaceted task, since conventional methodologies focused on TRL have proved insufficient to guarantee that wave energy technologies meet their technical and economic goals.

The authors presented a design domains framework that can provide wave energy engineers with a systematic means to guide the synthesis and analysis activities, avoiding quantum leaps from the 
initial requirements to the physical realisation that often leads to cost and schedule overruns. Besides, matrix-based design methods enable designers to arrange conceptual design information, understand complex interactions, quantify interrelationships and propagate information across design domains. The satisfaction of the requirements is the driving force in SE and must be an evidence-based process that relies on well-defined metrics. Multi-criteria analysis methods should be used to inform the decision-making process for the selection of solutions.

To date, the application of SE in wave energy is limited and fragmented. The most comprehensive SE exercise for a grid-connected wave energy farm was carried out in Wave-SPARC, sponsored by the US Department of Energy. Future efforts will expand its capability to the various blue economy maritime markets, including the specifications of the requirements, the adaptation of the TPL methodology and the application of innovation techniques such as TRIZ.

At a global level, the IEC Technical Committee 114 is making significant efforts to prepare international standards for marine energy conversion systems, including the conversion of wave, tidal and other water current energies into electrical energy. These technical specifications are contributing to the definitions of the TR and MR, as well as to the performance metrics for wave energy. On top of this, IEA-OES Task 12-Performance Metrics International Framework for Ocean Energy is building clarity, information and understanding to support the definition of a fully defined set of metrics and success thresholds for ocean energy technologies.

There is a wide scope of applicability of SE design methods in the wave energy sector. SE can support the development of effective and economically viable wave energy technologies in several ways:

- Environmental domain. Even though attributes that characterise SD are fairly covered for wave energy, the interaction and prioritisation among each other is still to be investigated.

- Stakeholder domain. Despite the underpinning research that assists in the identification of wave energy stakeholders, stakeholder prioritisation has not been carried out in a systematic manner. Moreover, the elicitation of SR largely depends on the type of market being addressed. Further research efforts should be devoted to the development of a more integrated and objective approach to stakeholder analysis for various potential markets of wave energy technologies.

- Functional domain. The analysis of FR for wave energy systems is reasonably well-covered in the literature. There is also a growing awareness on the need to define functional performance measures to judge the success of wave energy technologies beyond the contemporary TRL assessment and ongoing work to gain international consensus on the development of performance metrics. Although this is very positive, there is still the need for methods that establish the relative importance of FR and their interactions.

- Technical and process domains. The technical breakdown of wave energy systems in main typologies is well-documented. As TR are quite specific to the design solution, there is little information on the allocation of FR to the physical architecture or how TPMs are used to make decisions on the design options explored and the sizing of components. No references have been found in the literature on the development of MR specific for WEC devices. A structured analysis of the key design parameters and process variables that should be accounted for at early design phases would greatly facilitate the decision-making process.

- Evaluation and selection. Wave energy system development, evaluation and selection is moving progressively from simplified approaches such as assessing technology maturity and cost to more holistic performance measures. Selection at the intermediate stages of a system design contributes to reducing the risks. Iterations at low TRLs until the desired performance is achieved will contribute to the analysis of the solution space and the production of more cost-effective designs. However, further investigation on the aggregation hierarchy for the different evaluation criteria is required. 
In summary, a systematic design approach is still to be developed aiming to guarantee that SR are fully traceable throughout the wave energy design process to visualise complex system information and customise the assessment to highly changing market conditions. A key challenge in this approach lies in the uncertainties associated with the evaluation of the technologies at the early stages of development, where little details and evidence exist to quantify the metrics, as was identified in the present paper. However, the development of systematic design tools such as DTOceanPlus can assist engineers in translating requirements into feasible designs, identifying weaknesses and proposing possible solutions based on objective criteria.

Author Contributions: Conceptualisation P.R.-M.; methodology, P.R.-M.; writing-original draft, P.R.-M.; writing-review and editing, V.N., J.H. and J.M.B.; visualisation, V.N.; validation, J.H.; supervision, J.M.B. and funding acquisition, P.R.-M. and J.M.B. All authors have read and agreed to the published version of the manuscript.

Funding: This work was partially supported by the European Union's Horizon 2020 research and innovation programme under grant agreement no. 785921, project DTOceanPlus (Advanced Design Tools for Ocean Energy Systems Innovation, Development and Deployment).

Acknowledgments: Authors would like to thank the Basque Government through the research groups IT1314-19 and GIU19/276 and the Scottish Government for the support of Wave Energy Scotland.

Conflicts of Interest: The authors declare no conflict of interest.

\section{Abbreviations}

The following nomenclature and abbreviations are used in this manuscript:

AHP, Analytical Hierarchy Process; BOCR, Benefits, Opportunities, Costs and Risks; CAPEX, Capital Expenditure; DEA, Data Envelopment Analysis; DfX, Design for X; EMEC, European Marine Energy Centre; FMEA, Failure Modes and Effects Analysis; FR, Functional Requirements; FTA, Fault Tree Analysis; HMRC, Hydraulics \& Maritime Research Centre of the University College Cork; IEA-OES, International Energy Agency Collaboration Programme for Ocean Energy Systems; IEC, International Electrotechnical Commission; JRC, Joint Research Centre; LCOE, Levelised Cost of Energy; LSP, Logical Scoring of Preference; MAUT, Multi-Attribute Utility Theory; MBSE, Model-Based Systems Engineering; MOE, Measure of Effectiveness; MOP, Measure of Performance; MR, Manufacturing Requirements; MRL, Manufacturing Readiness Level; NREL, National Renewable Energy Laboratory; OPEX, Operational Expenditure; OWC, Oscillating Water Column; OWSC, Oscillating Wave Surge Converter; PESTLE, Political, Economic, Social, Technological, Legal and Environmental; PNNL, Pacific Northwest National Laboratory; PTO, Power Take-Off; QDF, Quality Function Deployment; SBD, Set-Based Design; SD, System Drivers; SE, Systems Engineering; SR, Stakeholder Requirements; SSG, Sea-wave Slot-cone Generator; TPL, Technology Performance Level; TRL, Technology Readiness Level; TPM, Technical Performance Measure; TR, Technical Requirements; TRIZ, Teoriya Resheniya Izobretatelskikh Zadatch (Theory of Inventive Problem Solving); TS, Technical Specification; WEC, Wave Energy Converter and WES, Wave Energy Scotland.

\section{References}

1. INCOSE. Systems Engineering Vision 2025. 2014. Available online: https://www.incose.org/docs/defaultsource/aboutse/se-vision-2025.pdf (accessed on 19 October 2020).

2. Corbett, J. Design for economic manufacture. Ann. CIRP 1986, 35, 93. [CrossRef]

3. Dowlatshahi, S. Product design in a concurrent engineering environments an optimization approach. J. Prod. Res. 1992, 30, 1803-1818. [CrossRef]

4. Ulman, D.G. The Mechanical Design Process, 4th ed.; McGraw-Hill: New York, NY, USA, 2010.

5. Trueworthy, A.M.; DuPont, B.L.; Maurer, B.D.; Cavagnaro, R.J. A set-based design approach for the design of high-performance wave energy converters. In Proceedings of the 13th European Tidal and Wave Energy Conference, Naples, Italy, 1-6 September 2019.

6. Fabrycky, W.J. Evaluation in systems engineering. In Systems Engineering and Management for Sustainable Development; EOLOSS: Oxford, UK, 2009; Volume 2, pp. 20-40.

7. Bayer, T. The Need for an Integrated Model-Centric Engineering Environment at JPL. IOM 3100-09-040 (Internal Memorandum); NASA Jet Propulsion Laboratory: Pasadena, CA, USA, 2009.

8. Wingate, L.M. Systems Engineering for Projects: Achieving Positive Outcomes in a Complex World; CRC Press: Boca Raton, FL, USA, 2019.

9. Yung, K.L. Application of Function Deployment Application of Function Deployment Model in Decision Making for New Product Development. Concurr. Eng. 2006, 14, 257-267. [CrossRef] 
10. De Girard, P.-H.-J.; de Girard, P.-H. Divers Moyens D'employer Les Vagues de la Mer Comme Moteurs; Office National de la Propriété Industrielle: Paris, France, 1799.

11. EMEC. Wave Developers. 2020. Available online: http://www.emec.org.uk/marine-energy/wave-developers/ (accessed on 19 October 2020).

12. Magagna, D. Ocean Energy Technology Development Report 2018; European Commission: Luxemburg, 2019.

13. Lynn, P.A. Electricity from Wave and Tide: An Introduction to Marine Energy; Wiley: Chichester, UK, 2014.

14. Greaves, D.; Iglesias, G. Wave and Tidal Energy; Wiley: Hoboken, NJ, USA, 2018.

15. Babarit, A. Ocean Wave Energy Conversion: Resource, Technologies and Performance; Elsevier: Oxford, UK, 2017; p. 262, ISBN 9781785482649.

16. BiMEP. Mutriku Site. 2020. Available online: https://www.bimep.com/en/mutriku-area/technical-characteristics/ (accessed on 19 October 2020).

17. OceanEnergy Ltd. What is the OE Buoy? 2020. Available online: https://oceanenergyusa.com/oe-buoy/ (accessed on 19 October 2020).

18. EMEC. Our Clients: Pelamis Wave Power. 2020. Available online: http://www.emec.org.uk/about-us/waveclients/pelamis-wave-power/ (accessed on 19 October 2020).

19. Seapower Ltd. Technology. 2020. Available online: http://www.seapower.ie/our-technology/ (accessed on 19 October 2020).

20. Wello, Oy. The Penguin Wave Energy Converter. 2020. Available online: https://wello.eu/the-penguin-2/ (accessed on 19 October 2020).

21. Carnegie Clean Energy. CETO Technology. 2020. Available online: https://www.carnegiece.com/technology/ (accessed on 19 October 2020).

22. AW Energy, Oy. WaveRoller. 2020. Available online: https://aw-energy.com/waveroller/ (accessed on 19 October 2020).

23. WavePiston. Technology. 2020. Available online: http://wavepiston.dk/\#our-services (accessed on 19 October 2020).

24. WaveDragon ApS. Technology. 2020. Available online: http://www.wavedragon.net/forside-2-2-2/ (accessed on 19 October 2020).

25. WAVEnergy. SSG Working Principle. 2020. Available online: https://www.waveenergy.no/workingprinciple/ (accessed on 19 October 2020).

26. Checkate Seaenergy. Anaconda Technology. 2020. Available online: https://www.checkmateukseaenergy. com/anaconda-technology/ (accessed on 19 October 2020).

27. Bombora Wave Power. mWave Technology. 2020. Available online: https://www.bomborawave.com/mwave/ (accessed on 19 October 2020).

28. Buede, D.M. The Engineering Design of Systems: Models and Methods, 2nd ed.; Wiley Publishing: Hoboken, NJ, USA, 2009.

29. INCOSE. Systems Engineering Handbook: A Guide for System Life Cycle Processes and Activities, 4th ed.; John Wiley and Sons, Inc.: Hoboken, NJ, USA, 2015.

30. Kamrani, A.A.M. Systems Engineering Tools and Methods; CRC Press: Boca Raton, FL, USA, 2011.

31. Micaëlli, J.-P.; Deniaud, S.; Bonjour, É.; Loise, D. How to implement the abstract design paradigm: The case of requirements engineering. Int. J. Prod. Dev. 2013, 18, 147-167. [CrossRef]

32. ISO/IEC/IEEE 15288. Systems and Software Engineering-System Life Cycle Processes; ISO/IEC/IEEE: Geneva, Switzerland, 2015.

33. ISO/IEC/IEEE 24748-4. Systems and Software Engineering_Life Cycle Management_Part 4: Systems Engineering Planning; ISO/IEC/IEEE: Geneva, Switzerland, 2016.

34. EIA-632. Processes for Engineering a System; TechAmerica: Washington, DC, USA, 2003.

35. Gausemeier, J.; Dumitrescu, R.; Steffen, D.; Tschirner, C.; Czaja, A.; Wiederkehr, O. Systems Engineering in industrial Practice. Heinz Nixdorf Institute; Fraunhofer Institute for Production Technology, Unity AG: Paderborn, Germany, 2015.

36. Pahl, G.; Beitz, W.; Feldhusen, J.; Grote, K.-H. Engineering Design: A Systematic Approach, 3rd ed.; Springer: London, UK, 2007.

37. Suh, N. Axiomatic Design: Advances and Applications; Oxford University Press: Oxford, UK, 2001.

38. National Research Council. Improving Engineering Design: Designing for Competitive Advantage; The National Academies Press: Washington, DC, USA, 1991. 
39. Eppinger, S.; Browning, T. Design Structure Matrix Methods and Applications; MIT Press: Cambridge, MA, USA, 2012.

40. Tichem, M. A Design Coordination Approach to Design for X; Delft University Press: Delft, The Netherlands, 1997.

41. Mizuno, S.; Akao, Y. QFD: The Customer-driven Approach to Quality; Asian Productivity Organization: Tokyo, Japan, 1994.

42. McDermott, R.; Mikulak, R.; Beauregard, M. The Basics of FMEA, 2nd ed.; Productivity Press: New York, NY, USA, 2008.

43. Altshuller, G. The Innovation Algorithm: TRIZ, Systematic Innovation and Technical Creativity; Technical Innovation Center: Worcester, MA, USA, 1999.

44. Haberfellner, R.; de Weck, O.; Fricke, E.; Vössner, S. Systems Engineering: Fundamentals and Applications; Birkhäuser: Cham, Switzerland; Springer Nature Switzerland AG: Cham, Switzerland, 2019.

45. Bartolomei, J.E.; Hastings, D.E.; de Neufville, R.; Rhodes, D.H. Engineering systems multiple-domain matrix: An organizing framework for modeling large-scale complex systems. Syst. Eng. 2012, 15, 41-61. [CrossRef]

46. Wasson, C.S. System Engineering Analysis, Design, and Development: Concepts, Principles, and Practices, 2nd ed.; Wiley: Hoboken, NJ, USA, 2016.

47. Hansen, C.H.; Andreasen, M.M. Two approaches to synthesis based on the domain theory. In Engineering Design Synthesis: Understanding, Approaches and Tools; Springer: London, UK, 2002; pp. 93-108.

48. Erens, F.J. The Synthesis of Variety: Developing Product Families; Technische Universiteit Eindhoven: Eindhoven, The Netherlands, 1996.

49. Farid, A.M.; Suh, N.P. Axiomatic Design in Large Systems: Complex Products, Buildings and Manufacturing Systems; Springer International Publishing AG: Cham, Switzerland, 2016.

50. Dahai, L. Systems Engineering: Design Principles and Models; CRC Press: Boca Raton, FL, USA, 2016.

51. Crowder, J.A.; Carbone, J.N.; Demijohn, R. Multidisciplinary Systems Engineering: Architecting the Design Process; Springer International Publishing: Cham, Switzerland, 2016; ISBN 978-3-319-22397-1.

52. Maurer, M.S. Structural Awareness in Complex Product Design; Technischen Universität München: Munich, Germany, 2007.

53. Steward, D.V. The design structure system: A method for managing the design of complex systems. IEEE Trans. Eng. Manag. 1981, 3, 71-74. [CrossRef]

54. Allen, T.T. Introduction to Engineering Statistics and Six Sigma: Statistical Quality Control and Design of Experiments and Systems; Springer: London, UK, 2006.

55. Kusiak, A.P. Interface structure matrix for analysis of products and processes. In Proceedings of the 15th CIRP International Conference on Life Cycle Engineering, LCE 2008, Sydney, Australia, 17-19 March 2008.

56. Danilovic, M.; Browning, T. Managing complex product development projects with design structure matrices and domain mapping matrices. Int. J. Proj. Manag. 2007, 25, 300-314. [CrossRef]

57. Hill, J.D.; Warfield, J.N. Unified program planning. IEEE Trans. Syst. Man Cybern. 1972, 5, 610-621. [CrossRef]

58. Mital, A.; Desai, A.; Subramanian, A.; Mital, A. Designing for functionality. In Product Development: A Structured Approach to Consumer Product Development, Design, and Manufacture; Elsevier: Amsterdam, The Netherlands, 2008; pp. 269-334.

59. Kar, P.; Bailey, M. Characteristics of Good Requirements; INCOSE: Boston, MA, USA, 1996.

60. Rogstrand, V.; Kjellberg, T. The representation of manufacturing requirements in model-driven parts manufacturing. Int. J. Comput. Integr. Manuf. 2009, 22, 1065-1072. [CrossRef]

61. Burge, S. A Functional Approach to Quality Function Deployment; Burge Hughes Walsh: Rugby, UK, 2007.

62. Sage, P.; Rouse, W.B. Handbook of Systems Engineering and Management, 2nd ed.; Wiley: Hoboken, NJ, USA, 2009.

63. Roedler, G.J.; Jones, C. Technical Measurement: A Collaborative Project of PSM, INCOSE, and Industry; INCOSE-TP-2003-020-01; International Council on Systems Engineering (INCOSE): San Diego, CA, USA, 2005.

64. Chevallier, J.; Marshall, R.M. SpecRight: Writing correctly requirements, produce product specification and requirement justification file. In Proceedings of the INCOSE International Symposium, Toulouse, France, 20-24 June 2004.

65. Yilmaz, S.; Daly, S.R.; Seifert, C.M.; Gonzalez, R. Design heuristics in ideation across engineering and industrial design domains. In Proceedings of the International Conference on Engineering and Product Design Education, Trondheim, Norway, 2-3 September 2010. 
66. Ishizaka, A. Multi-Criteria Decision Analysis: Methods and Software; John Wiley \& Sons Ltd.: Chichester, West Sussex, UK, 2013.

67. Keeney, R.L.; Raiffa, H. Decisions with Multiple Objectives: Preferences and Value Tradeoffs; John Wiley: New York, NY, USA, 1976.

68. Saaty, T. The Analytic Hierarchy Process; McGraw-Hill: New York, NY, USA, 1980.

69. Charnes, A.; Cooper, W.W.; Rhodes, E. Measuring the Efficiency of Decision Making Units. Eur. J. Oper. Res. 1978, 2, 429-444. [CrossRef]

70. Dujmovic, J.J. A method for evaluation and selection of complex hardware and software systems. In Proceedings of the 22nd International Conference for the Resource Management and Performance Evaluation of Enterprise Computer Systems, San Diego, CA, USA, 8-13 December 1996; Volume 1, pp. 368-378.

71. Bouzarour-Amokrane, Y.; Tchangani, A.; Peres, F. Defining and measuring risk and opportunity in BOCR framework for decision analysis. In Proceedings of the 9th International Conference on Modeling, Optimization \& Simulation, Bordeaux, France, 6-8 June 2012.

72. Cooper, R. The Stage-Gate Idea-to-Launch Process: Update, What's New and NexGen Systems. J. Prod. Innov. Manag. 2008, 25, 213-232. [CrossRef]

73. Vesely, W.E.; Stamatelatos, M.; Dugan, J.; Fragola, J.; Railsback, J.M.Y.J. Fault Tree Handbook with Aerospace Applications; NASA Office of Safety and Mission Assurance: Washington, DC, USA, 2002.

74. Ross, T.J. Fuzzy Logic with Engineering Applications, 4th ed.; Wiley: Chichester, West Sussex, UK, 2017.

75. Fenton, N.; Neil, M. Risk Assessment and Decision Analysis with Bayesian Networks, 2nd ed.; CRC: Boca Raton, FL, USA, 2019.

76. Brandimarte, P. Handbook in Monte Carlo Simulation: Applications in Financial Engineering, Risk Management, and Economics; Wiley: Hoboken, NJ, USA, 2014.

77. Costello, R.; Pecher, A. Chapter 5: Economics of WECs. In Handbook of Ocean Wave Energy; Springer: Berlin/Heidelberg, Germany, 2017; pp. 101-137.

78. Magagna, D.; Margheritini, L. Workshop on Identification of Future Emerging Technologies in the Ocean Energy Sector; European Commission: Luxembourg, 2018.

79. Bucher, R. Strategic Risk Management for Tidal Current and Wave Energy Projects; The University of Edinburgh: Edinburgh, UK, 2018.

80. Weber, J.; Mouwen, F.; Parish, A.; Robertson, D. Wavebob-Research \& development network and tools in the context of systems engineering. In Proceedings of the 8th European Wave and Tidal Energy Conference, Uppsala, Sweden, 7-10 September 2009.

81. da Rocha, A.B.; Lino, F.J.; Correia, N.; Matos, J.C.; Marques, M.; Morais, T. Offshore renewable energy development of ocean technology projects at Inegi. In Proceedings of the VI Cuban Congress on Mechanical Engineering and Metellurgy, Havanna, Cuba, 29 November-3 December 2010.

82. Toman, W.; Dooher, B.P.; Williams, R.B.; Slater, M.A.; Bedard, R. Bedard. In PGEE's WaveConnect ${ }^{\mathrm{TM}}$ Wave $^{\text {(n) }}$ Energy Power Pilot Project: Engineering Aspects; OCEANS 2009: Biloxi, MS, USA, 2009.

83. Ringsberg, J.W.; Jansson, H.; Yang, S.-H.; Örgård, M.; Johnson, E. Comparison of mooring solutions and array systems for point absorbimg wave energy devices. In Proceedings of the ASME 2018 37th International Conference on Ocean, Offshore and Arctic Engineering, Madrid, Spain, 17-22 June 2018.

84. 4c Engineering. FEED of AWS-III Wave Energy Convertor. 2020. Available online: https://www.4cengineering. co.uk/case-studies/feed-aws-iii-wave-energy-convertor/ (accessed on 19 October 2020).

85. Bull, D.; Roberts, J.; Malins, R.; Babarit, A.; Weber, J.; Dykes, K.; Nielsen, K.; Bittencourt-Ferreira, C.; Costello, R.; Kennedy, B. Systems engineering applied to the development of a wave energy farm. In Proceedings of the 2nd International Conference on Renewable Energies Offshore (RENEW2016), Lisbon, Portugal, 24-26 October 2016.

86. Sandberg, A.B.; Klementsen, E.; Muller, G.; de Andres, A. Critical Factors Influencing Viability of Wave Energy Converters in Off-Grid Luxury Resorts and Small Utilities. Sustainability 2016, 8, 1274. [CrossRef]

87. De Andres, A.; MacGillivray, A.; Roberts, O.; Guanche, R.; Jeffrey, H. Beyond LCOE: A study of ocean energy technology development and deployment attractiveness. Sustain. Energy Technol. Assess. 2017, 19, 1-16. [CrossRef]

88. Bhattacharya, S.; Preziuso, D.C.; Alam, M.E.; O’Neil, R.S.; Bhatnagar, D. Understanding the Grid Value Proposition of Marine Energy: An Analytical Approach; National Technical Information Service: Alexandria, VA, USA, 2019. 
89. Cantarero, M.V. D8.1 Potential Markets for Ocean Energy. DTOceanPlus. 2020. Available online: https://www. dtoceanplus.eu/Publications/Deliverables/Deliverable-D8.1-Potential-Markets-for-Ocean-Energy (accessed on 19 October 2020).

90. Ruiz-Minguela, P.; Blanco, J.M.; Nava, V. Novel methodology for holistic assessment of wave energy design options. In Proceedings of the 13th European Tidal and Wave Energy Conference, Naples, Italy, 1-6 September 2019.

91. Isakhanyan, G. Stakeholder Analysis of Marine Parks; Innovation Network: Utrecht, The Netherland, 2011.

92. Stagonas, D.; Myers, L.; Bahaj, A. D5.8: Impacts upon Marine Energy Stakeholders. EQUIMAR. 2011. Available online: https://www.equimar.org/equimar-project-deliverables.html/ (accessed on 19 October 2020).

93. Babarit, A.; Bull, D.; Dykes, K.; Malins, R.; Nielsen, K.; Costello, R.; Roberts, J.; Ferreira, C.; Kennedy, B.; Weber, J. Stakeholder requirements for commercially successful wave energy converter farms. Renew. Energy 2017, 113, 742-755. [CrossRef]

94. Del Rosario, V.; Goh, K.H. Community Stakeholder Management in Wind Energy Development Projects: A Planning Approach; Umeå University: Umeå, Sweden, 2008.

95. Mitchell, R.K.; Agle, B.R.; Wood, D.J. Toward a Theory of Stakeholder Identification and Salience: Defining the Principle of Who and What Really Counts. Acad. Manag. Rev. 1997, 4, 853-886. [CrossRef]

96. Sandia National Laboratories. Wave-SPARC. 2020. Available online: https://energy.sandia.gov/programs/ renewable-energy/water-power/projects/wave-sparc/ (accessed on 19 October 2020).

97. Bull, D.; Costello, R.; Babarit, A.; Nielsen, K.; Kennedy, B.; Bittencourt-Ferreira, C. Scoring the Technology Performance Level (TPL) Assessment. In Proceedings of the 12th European Wave and Tidal Energy Conference (EWTEC2017), Cork, Ireland, 27 August-1 September 2017.

98. Jahanshahi, A.; Kamali, M.; Khalaj, M.; Khodaparast, Z. Delphi-based prioritization of economic criteria for development of wave and tidal energy technologies. Energy 2019, 167, 819-827. [CrossRef]

99. French, M.; Bracewell, R. The systematic design of economic wave energy converters. In Proceedings of the 5th International Offshore and Polar Engineering Conference, The Hague, The Netherlands, 11-16 June 1995.

100. French, M.J. Conceptual Design for Engineers, 3rd ed.; Springer: London, UK, 1998.

101. Realff, M.; Cao, J.; Collopy, P.; Curtis, W.; Durham, D.; Raffaelle, R.P. Systems Engineering for Clean and Renewable Energy Manufacturing in Europe and Asia; WTEC Panel Report; World Technology Evaluation Center, Inc.: Lancaster, PA, USA, 2013.

102. González-Gutiérrez, J.G. Multidisciplinary System Design Optimisation of Oscillating Water Column Power Plants: A Nonlinear Stochastic Approach. University of Valladolid. October 2015. Available online: https://www.semanticscholar.org/paper/Multidisciplinary-system-design-optimisation-of-a-Guti\% C3\%A9rrez-Gabriel/ea023d02b96457cc1e6d30721d1f44355169f8db (accessed on 19 October 2020).

103. Harris, R.E.; Johanning, L.; Wolfram, J. Mooring systems for wave energy converters: A review of design issues and choices. In Proceedings of the 3rd International Conference on Marine Renewable Energy, Blyth, UK, 7-9 July 2004.

104. ORE-Catapult. Control Requirements for Wave Energy Converters-Final Report. Wave Energy Scotland. 2016. Available online: https://www.waveenergyscotland.co.uk/strategic-activity/strategic-activity-2/landscaping/ control-requirements-for-wave-energy-converters/ (accessed on 19 October 2020).

105. WETFEET. D3.2-Engineering of OWC Critical Parts Related to Submergence for Large Scale Deployment. H2020. 29 June 2017. Available online: http://www.wetfeet.eu/wp-content/uploads/2018/09/WETFEETDeliverable-3.2.pdf (accessed on 19 October 2020).

106. Starling, M. Guidelines for Reliability, Maintainability and Survivability of Marine Energy Conversion Systems; EMEC BSI: London, UK, 2009.

107. Carcas, M.; Davies, G.; Edge, G. Wave \& Tidal Energy: State of the Industry; ClimateXChange: Edinburgh, UK, 2018.

108. Weber, J. WEC Technology Readiness and Performance Matrix-Finding the best research technology development trajectory. In Proceedings of the 4th International Conference on Ocean Energy, Dublin, Ireland, 17-19 October 2012.

109. Weber, J.; Costello, R.; Ringwood, J. WEC Technology Performance Levels (TPLs)—Metric for Successful Development of Economic WEC Technology. In Proceedings of the 10th European Wave and Tidal Energy Conference (EWTEC2013), Aalborg, Denmark, 2-5 September 2013. 
110. Wave Energy Scotland. Ocean Energy Stage Gate Metrics Validation Workshop. OCEAN-ERANET. 2017. Available online: https://ibrary.waveenergyscotland.co.uk/other-activities/design-tools-and-information/ relevant-projects-and-research/metrics/ocean-energy-stage-gate-metrics-validation-workshop/ (accessed on 19 October 2020).

111. DTOceanPlus. Advanced Design Tools for Ocean Energy Systems Innovation, Development and Deployment. 2020. Available online: https://www.dtoceanplus.eu/ (accessed on 19 October 2020).

112. Hodges, J.; Henderson, J.; Holland, M.; Soede, M.; Ruedy, L.; Weber, J.; Hume, D.; Ramsey, T.; Ruiz-Minguela, P. Task 12-International Technology Evaluation Framework for Ocean Energy. OES-IEA. 2020. Available online: https://www.ocean-energy-systems.org/oes-projects/performance-metrics-international-frameworkfor-ocean-energy/ (accessed on 19 October 2020).

113. Dallman, A.; Weber, J.; Schoenwald, D.; Moraski, L.; Jenne, D. Existing Ocean Energy Performance Metrics. Sandia Report. 2019. Available online: https:/www.google.com/url?sa=t\&rct=j\&q=\&esrc=s\&source=web\& cd=\&ved=2ahUKEwjr8fHMi8HsAhWl3OAKHZgTBOMQFjAAegQIAhAC\&url=https\%3A\%2F\%2Feereexchange.energy.gov\%2FFileContent.aspx\%3FFileID\%3D89a224a1-6062-4567-a52d-66ddca0aa158\&usg= AOvVaw1iFHtD90dht7bLZMrhGXqE (accessed on 19 October 2020).

114. DAU. Defense Acquisition Guidebook (DAG); Defense Acquisition University (DAU)/U.S. Department of Defense (DoD): Ft. Belvoir, VA, USA, 2010; Available online: https://www.dau.edu/tools/dag (accessed on 19 October 2020).

115. SDWED. D5.1 Generic WEC System Breakdown. Structural Design of Wave Energy Devices. Danish Council for Strategic Research. 2014. Available online: https://www.sdwed.civil.aau.dk/digitalAssets/97/97538_d5.1.pdf (accessed on 19 October 2020).

116. SI OCEAN. Ocean Energy: State of the Art. Strategic Initiative for Ocean Energy, Intelligent Energy Europe Project No. IEE/11/089. 2013. Available online: https://ec.europa.eu/energy/intelligent/projects/en/projects/si-ocean (accessed on 19 October 2020).

117. EQUIMAR. D5.2 Device classification template. Equitable Testing and Evaluation of Marine Energy Extraction Devices in Terms of Performance, Cost and Environmental Impact, FP7 Project No. 213380. 2011. Available online: https://www.equimar.org/equimar-project-deliverables.html/ (accessed on 19 October 2020).

118. Scharmann, N. Ocean Energy Conversion Systems: An Innovative Concept Approach. Technische Universität Hamburg. 2018. Available online: https://www.worldcat.org/title/ocean-energy-conversion-systems-aninnovative-concept-approach/oclc/1032375502 (accessed on 19 October 2020).

119. Greedy, L. Guidelines for Grid Connection of Marine Energy Conversion Systems. EMEC. 2009. Available online: http://www.emec.org.uk/guidelines-for-grid-connection-of-marine-energy-conversion-systems/ (accessed on 19 October 2020).

120. TC 114. Marine Energy—Wave, Tidal and Other Water Current Converters_Part 2: Marine Energy Systems—Design Requirements; International Electrotechnical Commission. 2019. Available online: https://webstore.iec.ch/ publication/62399 (accessed on 19 October 2020).

121. TC 114. Marine Energy_Wave, Tidal and Other Water Current Converters-Part 100: Electricity Producing Wave Energy Converters_-Power Performance Assessment; International Electrotechnical Commission. 2012. Available online: https://webstore.iec.ch/publication/7241 (accessed on 19 October 2020).

122. TC 114. Marine energy_Wave, Tidal and Other Water Current Converters_Part 30: Electrical Power Quality Requirements; International Electrotechnical Commission. 2018. Available online: https://webstore.iec.ch/ publication/28781 (accessed on 19 October 2020).

123. McNicoll, A. Guidelines for Manufacturing, Assembly and Testing of Marine Energy Conversion Systems. EMEC. 2009. Available online: http://www.emec.org.uk/guidelines-for-manufacturing-assembly-andtesting-of-marine-energy-conversion-systems/ (accessed on 19 October 2020).

124. Fitzgerald, J.; Bolund, B. Technology Readiness for Wave Energy Projects; ESB and Vattenfall classification system. In Proceedings of the 4th International Conference on Ocean Energy, Dublin, Ireland, 17-19 October 2012.

125. De Rose, A.; Buna, M.; Strazza, C.; Olivieri, N.; Stevens, T.; Peeters, L.; Tawil-Jamault, D. Technology Readiness Level: Guidance Principles for Renewable Energy Technologies; European Commission. 2017. Available online: https://op.europa.eu/en/publication-detail/-/publication/1da3324e-e6d0-11e7-9749-01aa75ed71a1 (accessed on 19 October 2020). 
126. De Andres, A.; Medina-Lopez, E.; Crooks, D.; Roberts, O.; Jeffrey, H. On the reversed LCOE calculation: Design constraints for wave energy commercialization. Int. J. Mar. Energy 2017, 18, 88-108. [CrossRef]

127. Hutcheson, J.; de Andrés, A.; Jeffrey, H. Risk vs. Reward: A Methodology to Assess Investment in Marine Energy. Sustainability 2016, 8, 873.

128. HMRC. OCEAN ENERGY: Development \& Evaluation Protocol, Part 1: Wave Power; Marine Institute of Ireland. 2003. Available online: https://www.seai.ie/publications/HMRC-Protocall.pdf (accessed on 19 October 2020).

129. Holmes, B.; Nielsen, K. Guidelines for the Development \& Testing of Wave Energy Systems. OES-IA Annex II Task 2.1. 2010. Available online: https:/www.google.com/url?sa=t\&rct=j\&q=\&esrc=s\&source= web\&cd=\&ved=2ahUKEwiHqqOjkcHsAhWRoBQKHRMNAOgQFjABegQIAxAC\&url=http\%3A\%2F\% 2Foceanenergysystems.org\%2Fdocuments\%2F87102_annex_ii_summery_report_august_.pdf\%2F\&usg= AOvVaw06X1TNcIphgxqywperWApW (accessed on 19 October 2020).

130. Ingram, D.M.; Smith, G.H.; Bittencourt-Ferreira, C.; Smith, H. Protocols for the Equitable Assessment of Marine Energy Converters; EQUIMAR: Edinburgh, UK, 2011.

131. IEC. TC 114. Marine Energy_Wave, Tidal and Other Water Current Converters_Part 103: Guidelines for the Early Stage Development of Wave Energy Converters-Best Practices and Recommended Procedures for the Testing of Pre-Prototype Devices; IEC: Geneva, Switzerland, 2018.

132. Nava, V. D6.1 Technical Requirements for the Assessment Design Tools. DTOceanPlus. 2019. Available online: https://www.dtoceanplus.eu/Publications/Deliverables/Deliverable-D6.1-Technical-requirementsfor-the-assessment-design-tools (accessed on 19 October 2020).

133. Weber, J.; Costello, R.; Nielsen, K.; Roberts, J. Requirements for realistic and effective wave energy technology performance assessment criteria and metrics. In Proceedings of the 13th European Tidal and Wave Energy Conference, Naples, Italy, 1-6 September 2019.

134. Wave Energy Scotland. Project SEAWEED. 26 December 2019. Available online: https://www. waveenergyscotland.co.uk/strategic-activity/strategic-activity-2/structured-innovation/project-seaweed-1/ (accessed on 19 October 2020).

Publisher's Note: MDPI stays neutral with regard to jurisdictional claims in published maps and institutional affiliations.

(C) 2020 by the authors. Licensee MDPI, Basel, Switzerland. This article is an open access article distributed under the terms and conditions of the Creative Commons Attribution (CC BY) license (http://creativecommons.org/licenses/by/4.0/). 